\title{
Evaluation of Selection of Various Treatment Modalities Chosen by Subjects for Replacing Single Missing Tooth - A Questionnaire Survey in Western Maharashtra Population
}

\author{
Amit Bajirao Jadhav ${ }^{1}$, Pronob Kumar Sanyal², Priyanka Bharat Thorat ${ }^{3}$, Karuna Gajanan Pawashe ${ }^{4}$ \\ ${ }^{1}$ Department of Prosthodontics, School of Dental Sciences, Krishna Institute of Medial Sciences, \\ Deemed to Be University, Karad, Maharashtra, India. ${ }^{2}$ Department of Prosthodontics, School of Dental \\ Sciences, Krishna Institute of Medial Sciences, Deemed to Be University, Karad, Maharashtra, India. \\ ${ }^{3}$ Department of Orthodontics, School of Dental Sciences, Krishna Institute of Medial Sciences, Deemed \\ to Be University, Karad, Maharashtra, India. ${ }^{4}$ Department of Prosthodontics, School of Dental \\ Sciences, Krishna Institute of Medial Sciences, Deemed to Be University, Karad, Maharashtra, India.
}

\section{ABSTRACT}

\section{BACKGROUND}

This survey was done to evaluate awareness of various treatment modalities for replacing single missing tooth among the people of western Maharashtra. We wanted to assess gender wise awareness of patients regarding fixed dental prosthesis as a treatment modality for replacement of missing tooth.

\section{METHODS}

This cross-sectional study was done on 150 subjects visiting the dental college using a self-administered structured questionnaire. The questionnaire was pre-tested through a pilot survey. Data was evaluated using version 16.0 of the SPSS. Chi Square test and ANOVA were used as test of significance at $\mathrm{p}<0.05$.

\section{RESULTS}

Out of 150 subjects, 87 were males and 63 females. Around $64 \%$ of the subjects wanted to replace missing tooth due to difficulty in masticatory function; yet $14 \%$ knew the importance of aesthetic and speech as well. All subjects preferred fixed prosthesis for replacement of missing tooth, but higher cost of the procedure and fear of surgical trauma were the main factors for not undergoing implant treatment. Dental professionals were the main source of information about different treatment procedures followed by media.

\section{CONCLUSIONS}

There is a strong level of awareness among the subjects about the fixed treatment procedure, but more than half of the subjects did not have knowledge about the implants. It also revealed the need to provide the subjects with more knowledge about this treatment modality. Dental awareness is therefore necessary in order to cultivate a positive attitude towards dental implants amongst the community.
Corresponding Author: Dr. Amit Bajirao Jadhav, 10/10, Anupam, Lahoti Houses, Mangalwar Peth, Karad-415110, Distract-Satara, Maharashtra, India. E-mail: amit27986@gmail.com

DOI: $10.14260 /$ jemds/2020/413

Financial or Other Competing Interests: None.

How to Cite This Article:

Jadhav AB, Sanyal PK, Thorat PB, et al. Evaluation of selection of various treatment modalities chosen by subjects for replacing single missing tooth- a questionnaire survey in Western Maharashtra population. J. Evolution Med. Dent. Sci. 2020;9(26):1899-1902, DOI: $10.14260 /$ jemds/2020/413

Submission 03-04-2020,

Peer Review 29-05-2020,

Acceptance 05-06-2020,

Published 29-06-2020.

\section{KEY WORDS}

Dental Awareness, Fixed Dental Prosthesis, Single Missing Tooth 


\section{BACKGROUND}

We live in a social environment, and the way we look affects our relationships with others. Face and smile play a crucial role in establishing and maintaining positive attitudes about one's self and have immense emotional significance. ${ }^{1}$

Teeth play a vital role in maintaining a strong perception of oneself. ${ }^{2}$ The loss of one or more natural teeth often results in disability of essential daily living activities, such as speaking and eating are impaired, and also in being psychologically handicapped, as decreased social interaction because of embarrassment associated with loss.

Many treatment modalities are available for replacing a single missing tooth that includes removable partial denture, fixed partial denture or dental implant. Each modality is a possible treatment option and has its own advantage and disadvantage. The treatment of edentulism with removable prosthesis is less accepted than fixed partial denture and dental implant due to anatomical, physiological, psychological factors as well as prosthodontic factors like impaired masticatory function due to inadequate retention and stability, especially in the mandibular arch. ${ }^{3}$

The main role of prosthodontics is the rehabilitation of subjects with loss of teeth and oral function. Nonetheless, typically there are no established guidelines on how to measure the need, demand or use of prosthodontic resources in most cases. ${ }^{4}$ In certain cases, where more than one treatment choice is available, the final alternative depends on the decision/financial status of the patient, or is affected by the gender, age, public awareness and knowledge of the patient. Therefore, it is important to take into account the needs and demands of the patient to decide the form of care that ensures the fulfilment of the patient with the dental service. ${ }^{5}$

Despite the common concern with patient satisfaction in health care literature, there has been no consistent description of the principle or systematic analysis of its determinants and implications. There are actually many options available to address the problem of restoring a single tooth. In order to select the most appropriate treatment choice for each patient, each case should be assessed and all available options be reviewed. ${ }^{6}$ Awareness of these treatment modalities among the people, especially in developing countries is very less. ${ }^{7}$ Therefore, the aim of the present study was to assess gender wise the awareness of patient regarding fixed dental prosthesis as a treatment modality for replacement of missing tooth and provide complete information about fixed treatment therapies in order to help them choose the most appropriate option.

\section{METHODS}

A cross sectional study was conducted over a period of six months to gain access to the level of fixed dental prosthesis awareness among subjects coming to the dental college. Prior to the start of the survey, ethical permission was obtained from the Institute's Ethical Committee and written informed consent was obtained from all subjects. A sample of 180 subjects for this cross-sectional study was finalized based on total number of patients visiting the department of prosthodontics for the replacement of single missing tooth.

All the subjects coming to dental college who were willing to give informed consent and above 20 years of age were included. So out of 180, only 150 (87 males \& 63 females) agreed to participate in the survey and rest were excluded as they were not willing to give consent. A self-administered structured questionnaire was used to know information, included questions on awareness of subjects regarding various treatment modalities, preference for treatment modality, reason for the selection of treatment, preference for the superstructure \& sources which help subjects to know about treatment modalities etc.

For data analysis, a score of ' 1 ' was given to each positive response and a score of ' 0 ' was allocated to each negative response. Individual scores were summed up to give the total score. The Statistical software namely SPSS version 16.0 was used for the analysis of the data. Descriptive statistics were obtained, and frequency distribution were calculated by using Chi-square test and ANOVA test at $\mathrm{p}<0.05$.

\section{RESULTS}

The survey showed that around $64 \%$ (96) subjects wanted to replace missing tooth due to difficulty in masticatory function. 22\% (33) subjects selected aesthetics and 14\% (21) selected all i.e., aesthetic, function \& speech. Chi square $(0.02)$ and ANOVA $(\mathrm{P}=0.86)$ tests showed that preference of reason for replacing missing tooth among male and female subjects is similar i.e. Masticatory function. (Graph 1).

When it was asked regarding the awareness of different treatment modalities, 84\% (126) subjects showed awareness for both removable \& fixed prosthesis, $14 \%$ (21) showed awareness for fixed prosthesis \& $2 \%$ (3) subjects showed awareness only for removable prosthesis. Chi square (4.27) and ANOVA ( $\mathrm{p}=0.12)$ tests showed equal awareness among male and female subjects of different treatment modality for both removable and fixed prosthesis. All subjects preferred fixed prosthesis as treatment modality for replacement of missing tooth.

Out of 150 subjects, $86 \%$ (129) preferred fixed bridge prosthesis and 14\% (21) preferred implant for replacement of missing tooth. Of these 129 subjects who selected bridge for treatment, $60 \%$ (78) were male and $40 \%$ (51) were females. Of 21 Subjects who selected implant, 43\% (9) were male and $57 \%$ (12) were females. Chi square (2.29) and ANOVA ( $\mathrm{P}=0.13)$ tests showed that male and female subjects give more preference to bridge than implant. (Graph 2).

Out of 129 subjects who selected bridge for replacement of tooth- On asking about reasons for not selecting implant and preferring bridge; maximum i.e. 58\% (75) of the subjects did not opt for it due to its higher cost, majority of them were males $42 \%$ (54). 26\% were having fear of surgical trauma during implant insertion, majority of them were females $19 \%$. Some mentioned that it is time consuming $(7 \%)$ and around $9 \%$ did not want to go for complicated procedure. (Table 1) Out of 21 subjects who selected implant for replacement of tooth- 57\% (12) subjects selected implant because they believed that it has longer life as compared to bridge. $29 \%$ (6) selected implant due to conservation of adjacent tooth 
structure and only $14 \%$ (3) subjects selected as they are aesthetically better.

Out of 150, 56\% (84) subjects preferred PFM (porcelain fused to metal) prosthesis for the fabrication of superstructure. 24\% (36) preferred metal prosthesis and $20 \%$ (30) preferred all ceramic prosthesis. Chi square (5.35) and ANOVA $(\mathrm{P}=0.06)$ showed similar preference from male and female subjects for fabrication of superstructure i.e. PFM prosthesis. PFM \& All ceramic prosthesis were preferred for aesthetic reason in case of missing anterior tooth (74\%). $26 \%$ subjects preferred metal prosthesis for fabrication of superstructure due to high cost of ceramic materials and missing posterior tooth. Chi square test (2.73) and ANOVA $(p=0.09)$. According to the sources of obtaining information regarding treatment modalities, dental professionals were the main source of information (64\%) followed by media (16\%) like newspaper, TV etc, friends (12\%) and family members (8\%). Chi square test (6.84) and ANOVA $(\mathrm{P}=0.07)$ showed no significant difference between male and female subjects as more preference for source of information is given to Dentists. (Graph 3)

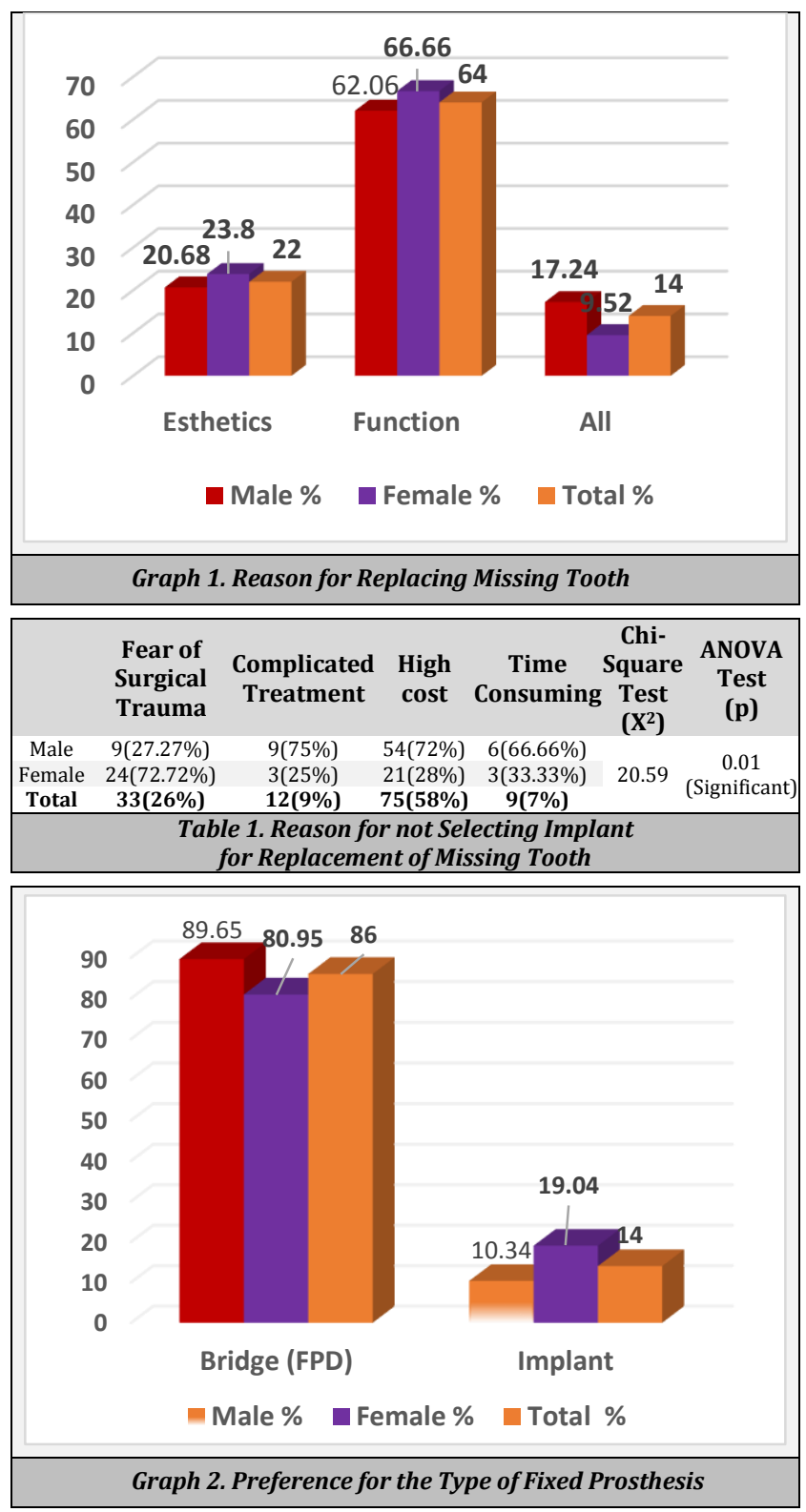

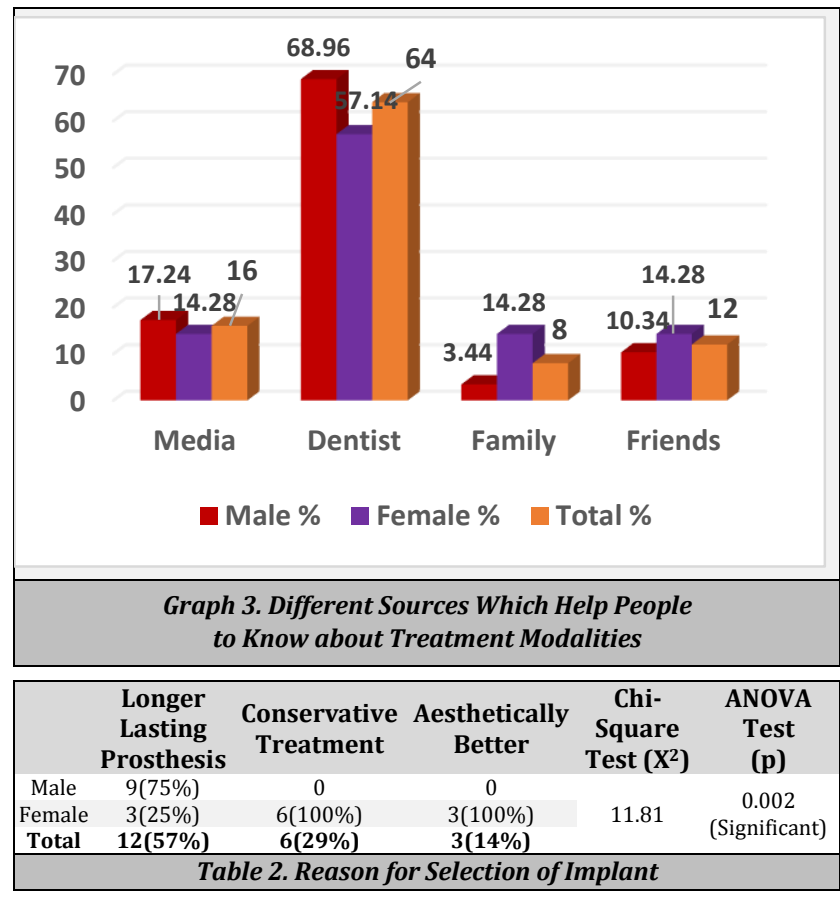

\section{DISCUSSION}

In India, epidemiological data on subjects' perceptions towards dental replacement are sparse. ${ }^{1}$ As a result, an attempt was made to determine the attitude towards the replacement of single missing tooth among subjects reporting to Dental College. Most of the subjects belonged to less than 40 years' age group. There were fewer subjects in the fortyone to fifty-five years' age groups because these subjects give a lower priority to dental health. Lack of knowledge and myths about the value of dental treatments have been recognized as contributing to this apparent lack of interest in dental care among these subjects. ${ }^{8}$

On asking about reason for missing tooth, subjects answered depending upon the type of tooth missing. Subjects who had missing molars gave masticatory function, the first priority. Subjects selected aesthetics to be of prime importance as it affected their appearance and their interaction with others. Most of them had missing premolars. Subjects who had missing incisors selected all; aesthetic, function and speech as their appearance, incising function and speech got affected.

On asking Reasons for not selecting implant for replacement of missing tooth higher frequency of population chose FPD due to high cost of implants, followed by fear of surgical trauma. Some people have different priorities like it is time consuming and complicated procedure. Similar results are obtained in the majority of preceding studies such as Kent et al. (1992), ${ }^{9}$ Zimmer et al. (1992), ${ }^{10}$ Tepper et al. (2003), ${ }^{11}$ Johani SA et al. (2010), ${ }^{12}$ Kaurani P et al. (2010). ${ }^{13}$ Chi-square (20.59) and ANOVA test $(\mathrm{P}=0.01)$ showed a significant difference according to gender as males gave preference to high cost of implants and females gave preference to fear of surgical trauma for not selecting implant (Table 1).

Similarly, regarding reason for implant selection showed significant difference as males selected implant because it is longer lasting prosthesis and females selected implant because of its conservative approach and aesthetic property. 
This survey noticed that $76 \%$ subjects selected Porcelain prosthesis because of its aesthetic reason and 24\% selected Metal prosthesis due to higher costs of ceramic Prosthesis. (Table 2).

The survey also found that only $14 \%$ of subjects had selected implants. The findings however were smaller than those of Zimmer et al (1992) ${ }^{8}$, Berge (2000) ${ }^{14}$ and Tepper et al (2003), ${ }^{9}$ which revealed an awareness level of $77 \%, 70.1 \%$ and $72 \%$ respectively. This may be attributed to a weak socio-economic status and a poor level of education among the study population. Whereas Chowdhary R et al. reported lower performance among the Indian population in 2010.15

Regarding the source of information our results were similar to study done by Johany SA et al (2010), ${ }^{10}$ which also stated that most of the people get aware about implants by the dental professionals. Media played the second most important role in source of information followed by friends and family. All the same, studies by Zimmer et al. (1992), Berge (2000),12 Best (1993), ${ }^{16}$ Showed that media was found to be the main source of information and dentists at best performed a secondary role. Akagawa et al. (1988) ${ }^{17}$ found that the information provided by dentists was not more than 20 percent.

\section{CONCLUSIONS}

Educational status and awareness different treatment procedures to replace single missing tooth have a major impact on the choice of treatment. Patient's awareness about replacement of missing tooth is more than average but, knowledge and attitude towards implants as an option for replacing missing tooth is below average. High cost of the implant is one of the major factors against the willingness of subjects to undergo this treatment. Subjects' perceptions towards replacement of tooth should be measured in order to inform the individual appropriately and to improve patient satisfaction with regard to prostheses.

\section{ACKNOWLEDGEMENT}

My sincere thanks to Dept. of Prosthodontics \& Crown and Bridge. I am also grateful to Krishna Institute of Medical Sciences University for permitting me to conduct this study.

\section{REFERENCES}

[1] Shigli K, Hebbal M, Angadi GS. Attitudes towards replacement of teeth among patients at the institute of dental sciences, Belgaum, India. J Den Educ 2007;71(11):1467-75.
[2] Roessler DM. Complete denture success for patients and dentists. Int Dent J 2003;53(5 Suppl):340-5.

[3] Balshi TJ, Wolfinger GJ, Hernandez RE. Patient attitude before and after dental implant rehabilitation. Implant Dent 1994;3(2):106-9.

[4] Bhat AM, Prasad KD, Sharma D, et al. Attitude toward desire for implant treatment in South Coastal Karnataka population: a short-term epidemiological survey. Int J Oral Implantol Clin Res 2012;3(2):63-6.

[5] Pandey A, Khurana P. Various factors influencing the treatment of single tooth replacement. Bhavnagar University's Journal of Dentistry 2013;3(3):8-17.

[6] Meyenberg KH, Imoberdorf MJ. The aesthetic challenges of single-tooth replacement: a comparison of treatment alternatives. Pract Periodontics Aesthet Dent 1997;9(7):727-35.

[7] Saha A, Dutta S, Vijaya V, et al. Awareness among patients regarding Implants as a treatment option for replacement of missing teeth in Chattisgarh. J Int Oral Health 2013;5(5):48-52.

[8] Maupome G, MacEntee MI. Prosthodontic profiles relating to economic status, social network, and social support in an elderly population living independently in Canada. J Prosthet Dent 1998;80(5):598-604.

[9] Kent G. Effects of Osseo-integrated implants on psychological and social well-being: a literature review. J Prosthet Dent 1992;68(3):515-8.

[10] Zimmer CM, Zimmer WM, Williams J, et al. Public awareness and acceptance of dental implants. Int J Oral Maxillofac Implants 1992;7(2):228-32.

[11] Tepper G, Haas R, Mailath G, et al. Representative marketing-oriented study on implants in the Austrian population. I. Level of information, sources of information and need for patient information. Clin Oral Implants Res 2003;14(5):621-33.

[12] Johany SA, Zoman HAA, Juhaini MA, et al. Dental subjects' awareness and knowledge in using dental implants as an option in replacing missing teeth: a survey in Riyadh, Saudi Arabia. Saudi Dent J 2010;22(4):183-8.

[13] Kaurani P, Kaurani M. Awareness of dental implant as a treatment modality amongst people residing in Jaipur (Rajasthan). J Clin Diagn Res 2010;4:3622-6.

[14] Berge TI. Public awareness, information sources and evaluation of oral implant treatment in Norway. Clin Oral Implants Res 2000;11(5):401-8.

[15] Chowdhary R, Mankani N, Chandraker NK. Awareness of dental implants as a treatment choice in urban Indian populations. Int J Oral Maxillofac Implants 2010;25(2):305-8

[16] Best HA. Awareness and need of dental implants by patients in New South Wales. Aust Prosthodont J 1993;7:9-12.

[17] Akagawa Y, Rachi Y, Matsumoto T, et al. Attitudes of removable denture patients toward dental implants. J Prosthet Dent 1988;60(3):362-4. 